\title{
EsAsí
}

(ㄷ) (1) ()

El Premio para Jóvenes Traductores esAsí de la Embajada de España en Ljubljana, que inició su andadura en 2009, tiene por objeto reconocer y alentar la labor de los traductores noveles del español al esloveno.

El Premio para Jóvenes Traductores esAsí es de carácter bienal y se alterna con el Premio esAsí a la Mejor Traducción editada en esloveno de obras literarias escritas en español. Por su parte el Premio para Jóvenes quiere fomentar la difusión de la lengua española en Eslovenia y promover la actividad de los jóvenes traductores para que la cultura en español esté cada día más al alcance de todos los eslovenos. El premio está abierto a la participación de jóvenes traductores entre 18 y 30 años. Los textos originales son seleccionados por el jurado.

Traductores galardonados en las tres últimas convocatorias:

2009 Tina Šilc: Un buitre ba becho su nido en el café de Ignacio Aldecoa

2011 Nace Fock: El paracaidista de Juan Bonilla

2013 Laura Repovš y Andreja Udovč: Los Caynas de César Vallejo

A continuación se presentan las traducciones y la versión original de tres fragmentos de las obras antes mencionadas. 


\section{Ignacio Aldecoa}

\section{Jastreb je spletel gnezdo v kavarni (odlomek)}

Donje Francisquite je bila ena sama krepost; slonokoščen, čokat in nedostopen stolp kreposti. V kavarno je prihajala okrog enajstih, naročila lipov čaj in se pričela $\mathrm{s}$ svojim pomožnim bikoborcem in soprogom, donom Fortunatom, bogato in $\mathrm{v}$ en glas zgražati. Med obsojanjem in zavračanjem si je z udarci pahljače hladila materinske in tudi ognjevite prsi. Donja Francisquita je bila tako pregrešna v kreposti, kot so drugi ljudje krepostni v pregrehi in hkrati mislijo, da vse vedo. Don Fortunato je od časa do časa kot osel zarigal v znak soglasja z modrovanji svoje gospe, medtem ko je zalival svoj kurji britof $z$ janževcem.

- Ta je že tretji in tista, ki nosi posledice, je snažilka. Potem se pa nikar ne pritožuj čez vamp.

- Saj se ne pritožujem.

- Da se ne pritožuješe Življenje pa preživljaš na stranišču. - Donja Francisquita je zaupljivo zavila z usti:

- Poglej, Forti, poglej, kako se lisjak približuje kuzli. Kakšna sramota. Glej, človek, glej, in ne daj se motiti ...

- Že, že.

- Mar ne vidiš, kako se je hinavec prestavil od mizice k mizi ... Kakšen gnus ... Če je že tale prašič nagnusen ... Pa ona ... Kaj porečeš o njej? S tem ogromnim dekoltejem, da se ji vidi do ...

- Ja, ja ... - je dejal opazovalec don Fortunato.

- Ne glej je - je zaukazala donja Francisquita. - Ne glej tega izmečka ... Kakšne izzivalne kretnje in kakšna nespodobnost ... In ni samo ona, sem prihajajo tudi druge ... Jasno, če ima lastnik posel, moraš držati gobec ... Potem pa naj se nihče ne pritožuje zaradi izgubljenega dostojanstva, sramu in vsega, kar je mogoče izgubiti ... 


\section{Ignacio Aldecoa}

\section{Un buitre ha hecho su nido en el café (fragmento)}

Doña Francisquita era la virtud; la ebúrnea, achaparrada e inasequible torre de la virtud. Llegaba sobre las once al café, pedía su tila y comenzaba a horrorizarse tan ricamente y de consuno con su peón de brega y marido don Fortunato. Entre condena y repulsa se refrescaba la maternal, también briosa, pechuga a golpe de abanico. Doña Francisquita era una viciosa de la virtud como otras gentes son virtuosas del vicio y se las saben todas. Don Fortunato de vez en cuando rebuznaba una aquiescencia a la plática de su señora mientras cargaba la andorga de anís.

-Ésta es la tercera y la que paga las consecuencias es una servidora. Luego no te quejes de la barriga.

-No me quejo.

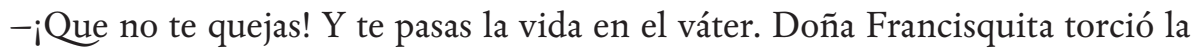
boca en la confidencia:

-Mira, Fortu, mira al zorro cómo se acerca a la zorra... Qué vergüenza. Mira, hombre, mira y no te distraigas...

- Ya, уа...

-Pero no ves cómo el camándula se ha cambiado del velador a la mesa... Pero qué asco... Si será asqueroso el tío gorrino... Y ella... ¿Qué me dices de ella? Con todo ese escotazo que se le ve hasta...

-Ya, ya... -dijo el observador don Fortunato.

-No la mires -ordenó doña Francisquita-. No mires esa basura... Y qué gestos tan provocativos y qué indecencia... Y no es ella sola, que viene por aquí cada una... Claro, como el dueño hace negocio, pues chitón... Y luego que nadie protesta, porque se ha perdido la dignidad, la vergüenza y todo lo que hay que perder... 


\section{Juan Bonilla}

\section{Padalec (odlomek)}

Nevidne roke ga držijo, čuti jih na prsih, po zaslugi rahlega, a neodjenljivega prijema niti opazi ne, da pada. Spodaj svet kot sestavljanka, razprostrto telo, koščki zemlje, spravljeni skupaj v obleko iz krp, makadamske in asfaltne ceste kot neštete žile organizma, ki bi lahko tudi brez vseh njih še naprej obstajal, nekaj gora, mišic iz skal in rastlinja, in na levem robu slepeče lesketanje jezera. Po žilah zleknjenega telesa se pomikajo barvasti gumbi, lenobne krvničke, avtomobili, ki bežijo iz mesta. Mesto: iz položaja, v katerem se nahaja padalec, je mesto trdovraten madež, ki izpušča $v$ zrak kopreno onesnaženja in hrupa. Med tlemi in padalcem je komajda nekaj majhnih belih oblakov, otočkov čiste pare, zaostalih za veliko četo, ki je sinoči prečkala nebo nad pokrajino.

Več kot minuto je že v zraku in padalca pričenja skrbeti. Zakaj se tla ne dvignejo k njemu? Zakaj mu v slušalki še ni zapiskalo v opozorilo, da mora odpreti padalo? Zakaj ga nevidne roke, ki jih še zmeraj čuti na prsih, ne izpustijo?

Vprašanja, vprašanja, vprašanja. Ne morejo spremeniti dejstva: pol ure po tem, ko je odskočil z letala, padalec še vedno visi v zraku, ne da bi se bil spustil za en sam meter, na isti točki, na tisoče čevljev nad gladino gorja, ga zadržujejo nevidne roke, iz prijema katerih se ne zna izviti.

Padalec je v sebi zatrl občutek tesnobe in nelagodja, ki ga je spravljal ob pamet. Zaspal je na tisočih čevljev nad gladino gorja, potem ko je bil v napadu panike spet in spet kričal, v upanju, da ga bo kdo slišal, ne da bi se zavedel, kako njegovi kriki, ki mu jih v glavi vsakokrat raznese kot z vso močjo ob steno zalučano zrelo hruško, nikakor ne preglasijo zvočnega zidu, ki vlada v višavah, kako ne sežejo niti pol metra od grla, iz katerega se mukoma izvijajo. Vdan v usodo kot obsojenec, ki samega sebe prepričuje, kako ima tem manj možnosti, da ohrani zdravo pamet, čim dlje se ne sprijazni z razsodbo, je padalec opustil iskanje jasne razlage, ki bi mu zagotovila občutek varnosti v novonastalih okoliščinah. Še zmeraj visi v zraku kot že nekaj ur tega, še vedno v primežu nevidnih rok, ki mu ne pustijo pasti, še vedno občuduje pokrajino tam spodaj, s skupaj zraščenimi travniki, po katerih se kdaj pa kdaj zganejo barvaste pike 
ali pa jih vznemirja samo počasno premikanje senc. Odpreti padalo ni ravno prepričljiva izbira: bilo bi tako kot do konca pohoditi zavoro $\mathrm{v}$ že ustavljenem avtomobilu. Med padalčevim telesom in zemljo se zdaj pase številčen trop oblakov. Nebesna preproga nad padalcem pričenja temneti. Sonce na njegovi desni ni več ognjena krogla, spremenilo se je v sočen sadež, v katerega bo zagrizlo nekaj gora. Njegov sok se bo razlil po obzorju, za zdaj še popolni krog se bo preoblikoval v pas oranžastega črnila, ki se bo naposled raztopilo, medtem ko bo po tunelih iz vesolja pričel curljati sij zvezd, ki so umrle pred stoletji, planetov na dosegu roke, zbirke draguljev, ki nam jo neznani trgovec vsako noč ponudi, tako da jo razprostre po temnem plašču neba, kakor bi bila nakit, s katerim naj si ozaljšamo prečudno dejstvo, da smo živi, pa da smo tako neznatni, četudi je edino sporočilo, ki ga vsa ta zbirka zvezd v resnici nosi, naj sprevidimo, da slavijo naš obstoj. Padalec ne čuti mraza, in ko se tega zave, je prepričan, da lahko le ena stvar pojasni vse, kar se mu godi: smrt. Pride do sklepa, da se ne more spustiti zato, ker je mrtev, ker ni več tisto, kar je bil, temveč se je spremenil v privid, v prebivalca gube, kamor se bo zatekel, dokler se ne bo dokončno razblinil.

Traducción: Nace Fock 


\section{Juan Bonilla}

\section{El Paracaidista (fragmento)}

Unas manos invisibles lo sostienen, las siente en el pecho, es una presión leve pero firme, la responsable de que no perciba que está cayendo. Abajo, el puzzle del mundo, un cuerpo tendido, trozos de tierra que conforman un vestido hecho de retales, los caminos de arena o asfalto como incontables venas de un organismo que podría prescindir de todas ellas para seguir existiendo, algunos montes, músculos de piedra y vegetación, y en el margen izquierdo el afilado brillo de un lago. Por las venas de ese cuerpo que yace avanzan botones de colores, glóbulos lentos, autos que escapan de la ciudad. La ciudad: desde la posición en la que se encuentra el paracaidista, la ciudad es una mancha abrupta que eleva al aire una gasa de contaminación y ruido. Entre el suelo y el paracaidista apenas se interponen unas cuantas nubes pequeñas y blancas, islotes de humo pudo que quedaron rezagados del gran pelotón que anoche cruzó el cielo de la provincia.

Ya lleva más de un minuto en el aire y el paracaidista empieza a inquietarse. ¿Por qué no sube el suelo hasta él? ¿Por qué no ha chillado ya su casco avisándole de que ha de abrir el paracaídas? ¿Por qué no le abandonan las manos invisibles que sigue sintiendo en el pecho?

Preguntas, preguntas, preguntas. Nada pueden contra un hecho: media hora después de arrojarse del avión, el paracaidista sigue colgado del aire, sin haber descendido un solo metro, sostenido en aquel punto, a miles de pies sobre el nivel del mal, por unas manos invisibles de las que no sabe cómo desasirse.

El paracaidista ha anulado en su interior la sensación de angustia y extrañeza que lo perturbaba. Se ha quedado dormido a miles de pies sobre el nivel del mal después de gritar una y otra vez, dominado por el pánico, esperando que alguien le oyese, sin reparar en que su voz, que en su propio cerebro estallaba como una pera madura arrojada con fuerza contra una pared, no lograba elevarse sobre la berrera de sonido neutro que impera en las alturas, no conseguía separarse ni medio metro de la garganta de la que emergía dolorosamente. Con la resignación de un condenado que se convence a sí mismo de que cuanto 
más se demore en aceptar el fallo menos posibilidades tendrá de conservar la cordura, el paracaidista ha desistido en la búsqueda de una explicación que le provea de seguridad acerca de su nueva situación. Sigue colgado en el aire, como hace horas, sigue sujeto por unas manos invisibles que le impiden caer, sigue contemplando allá abajo un paisaje de prados cicatrizados por los que de vez en cuando circulan puntos de colores y a los que sólo perturba el lento avance de las sombras. Abrir el paracaídas no es una opción convincente: sería como apretar a fondo el pedal de freno de un coche que está parado. Entre el cuerpo del paracaidista y la tierra pasta ahora un rebaño de nubes numeroso. Por encima del paracaidista el tapiz del cielo empieza a oscurecerse. A su derecha el sol ha dejado de ser una bola de fuego para convertirse en una fruta pletórica que va a recibir el mordisco de unos montes. Su jugo se esparcirá por el horizonte, el círculo perfecto que es todavía se transformará en un renglón de tinta anaranjada que acabará diluyéndose mientras por los túneles del espacio empiezan a chorrear su luz estrellas que murieron hace siglos, planetas al alcance de la mano, la colección de joyas que cada noche un mercader ignoto nos ofrece extendiéndola en el mantel oscuro del firmamento como si fuese bisutería con la que adornar la extrañeza extraordinaria de estar vivos, de ser tan insignificantes a pesar de que toda esa colección de astros, en el fondo, para lo único que sirve es para que nos demos cuenta de que están celebrando que existamos. El paracaidista no siente frío, y al reparar en ello, adquiere la convicción de que sólo hay una cosa que puede explicar lo que le ocurre: la muerte. Decide que si no logra descender es porque está muerto, porque ha dejado de ser lo que era para convertirse en un espejismo, habitante de un pliegue en el que se refugiará hasta borrarse definitivamente. 


\section{César Vallejo}

\section{Prebivalci Cayne (odlomek)}

[...] Na ves glas sem malodane ječe zaklical.

Nič. Vsa vrata sob so bila, kakor vrata na cesto, povsem odprta. Spustil sem uzdo svojega konja, stekel iz hodnika v hodnik, z dvorišča na dvorišče, iz sobe $\mathrm{v}$ sobo, iz tihote v tihoto; in nov krulež me je končno zaustavil pred betonskim stopniščem, ki se je vzpenjalo v najvišji in najmračnejši skedenj hiše. Prisluhnil sem. Zopet je vse postalo skrivnostno.

Niti sledi človeškega življenja; niti ene same domače živali. Čudne roke so morale razdejati, s sleparsko zmedo dobrega okusa in vsakršnega smisla za red ter udobje, običajno razporeditev pohištva, posode in drugih hišnih pripomočkov. Naglo, zapeljan od skrivne privlačnosti, sem planil po stopnicah tistega stopnišča; in ko sem se namenil odmakniti podstrešno loputo, sem jo ravno tako našel odprto. Tam me je zadržala nerazložljiva in vročična stiska; okleval sem nekaj kratkih sekund in v naklonjenosti še zadnjih žarkov dneva hlastno pogledal noter. Grozo zbujajoče besen, do smrti izprijen se je med sencami te jame poblisnil mršav in divji obraz. Zbral sem ves pogum - moj Bog, že sem sumil vse! -, da sem se zatekel med vratni podboj in se prisilil prepoznati to strašno masko.

Bil je obraz mojega očeta!

Opica! [...]

Traducción: Laura Repovš 


\section{César Vallejo}

\section{Los caynas (fragmento)}

[...] A toda voz llamé casi gimiendo.

Nada. Todas las puertas de las habitaciones estaban, como la de la calle, abiertas hasta el tope. Solté la brida de mi caballo, corrí de corredor en corredor, de patio en patio, de aposento en aposento, de silencio en silencio; y nuevos gruñidos detuviéronme por fin, delante de una gradería de argamasa que ascendía al granero más elevado y sombrío de la casa. Atisbé. Otra vez se hizo el misterio.

Ninguna seña de vida humana; ni un solo animal doméstico. Extrañas manos debían de haber alterado, con artimañoso desvío del gusto y de todo sentido de orden y comodidad, la usual distribución de los muebles y de los demás enseres y menaje del hogar.

Precipitadamente, guiado por secreta atracción, salté los peldaños de esa escalera; y, al disponerme a trasponer la portezuela del terrado, la advertí franca también. Detúvome allí inexplicable y calofriante tribulación; dudé por breves segundos, y, favorecido por los destellos últimos del día, avizoré ávidamente hacia adentro. Rabioso hasta causar horror, desnaturalizado hasta la muerte, relampagueó un rostro macilento y montaraz entre las sombras de esa cueva. Enristrando todo mi coraje -ipues que ya lo suponía todo, Dios mío!- me parapeté junto al marco de la puerta y esforcéme en reconocer esa máscara terrible.

¡Era el rostro de mi padre!

¡Un mono! [...] 


\section{César Vallejo}

\section{Cayničani (odlomek)}

Moj oče, takšen, kot sem ga videl tistega daljnega popoldneva, se je pojavil na pragu in sledila so mu zlovešča bitja, ki so groteskno kričala. Naglo so utrnila luč, ki sem jo nosil, in s preroško skrivnostnostjo kričala:

- Luč! Luč! ... Zvezda!

Obstal sem odrevenel, brez besed ...

In potem sem, ob nepravem času, zbral vse sile in obupano rotil:

- Oče moj! Spomni se, da sem tvoj sin! Ti nisi bolan! Ti ne moreš biti bolan! Pusti to vreščanje iz goščave! Ti nisi opica! Ti si človek, o, oče moj! Mi vsi smo ljudje! Ponovno sem prižgal plamen.

Krohot mi je s poševnim zamahom prebodel srce. In moj oče je s presunljivim obžalovanjem, poln neskončnega usmiljenja, zaječal:

- Nesrečnik! Domišlja si, da je človek! Nor je ...

Ponovno se je zmračilo.

In ves iz sebe od strahu sem se oddaljil od tiste temne skupine, z glavo nihajoč sem in tja.

- Nesrečnik! - so zakričali vsi - popolnoma nor je! ...

- In tukaj sem pred vami, norec - je žalostno dodal mož, ki nam je povedal tako čudno zgodbo.

Takrat se mu je približal uslužbenec, oblečen $\mathrm{v}$ rumeno uniformo in $\mathrm{v}$ brezbrižnost, mu namignil, naj mu sledi, in se hkrati na hitro, izmikajoče poslovil od nas.

- Nasvidenje. Peljem ga v njegovo celico. Nasvidenje.

In nori pripovedovalec te zgodbe se je $\mathrm{z}$ ramo ob rami izgubil skupaj s svojim bolničarjem, ki ga je vodil med zelenimi jelšami norišnice; tačas je morje grenko ihtelo in dve ptici sta se upirali v hropeča pleča večera ... 


\section{César Vallejo}

\section{Los caynas (fragmento)}

Mi padre, tal como le había visto aquella tarde, apareció en el umbral de la puerta, seguido de algunos seres siniestros que chillaban grotescamente. Apagaron de un revuelo la luz que yo portaba, ululando con fatídico misterio:

-¡Luz! ¡Luz!... ¡Una estrella!

Yo me quedé helado y sin palabra. Más, de modo intempestivo, cobré luego todas mis fuerzas para clamar desesperado:

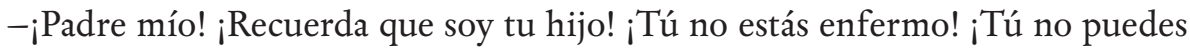
estar enfermo! ¡Deja ese gruñido de las selvas! ¡Tú no eres un mono! ¡Tú eres un hombre, oh, padre mío! ¡Todos nosotros somos hombres!

E hice lumbre de nuevo.

Una carcajada vino a apuñalarme de sesgo a sesgo el corazón. Y mi padre gimió con desgarradora lástima, lleno de piedad infinita.

${ }_{-}^{\text {¡P} P o b r e ! ~ S e ~ c r e e ~ h o m b r e . ~ E s t a ́ ~ l o c o . . . ~}$

La oscuridad se hizo otra vez. Y arrebatado por el espanto, me alejé de aquel grupo tenebroso, la cabeza tambaleante.

- ¡Pobre! -exclamaron todos- ¡Está completamente loco!...

-Y aquí me tienen ustedes, loco- agregó tristemente el hombre que nos había hecho tan extraña narración.

Acercósele en esto un empleado, uniformado de amarillo y de indolencia, y le indicó que le siguiera, al mismo tiempo que nos saludaba, despidiéndose de soslayo:

-Buenas tardes. Le llevo ya a su celda. Buenas tardes.

Y el loco narrador de aquella historia, perdióse lomo a lomo con su enfermero que le guiaba por entre los verdes chopos del asilo; mientras el mar lloraba amargamente y peleaban dos pájaros en el hombro jadeante de la tarde... 